듬 SCHOOL of GRADUATE STUDIES

EAST TENNESSEE STATE UNIVERSITY
East Tennessee State University Digital Commons@ East Tennessee State University

$5-2012$

\title{
Reflex of Avoidance in Spatial Restrictions for Signatures and Handwritten Entries
}

Linde Christine Rush Burkey

East Tennessee State University

Follow this and additional works at: https://dc.etsu.edu/etd

Part of the Criminology Commons

\section{Recommended Citation}

Burkey, Linde Christine Rush, "Reflex of Avoidance in Spatial Restrictions for Signatures and Handwritten Entries" (2012). Electronic Theses and Dissertations. Paper 1421. https://dc.etsu.edu/etd/1421

This Thesis - Open Access is brought to you for free and open access by the Student Works at Digital Commons @ East Tennessee State University. It has been accepted for inclusion in Electronic Theses and Dissertations by an authorized administrator of Digital Commons@ East Tennessee State

University. For more information, please contact digilib@etsu.edu. 
Reflex of Avoidance in Spatial Restrictions for Signatures and Handwritten Entries

\author{
A thesis \\ presented to \\ the faculty of the Department of Criminal Justice and Criminology \\ East Tennessee State University
}

In partial fulfillment

of the requirements for the degree

Master of Arts in Criminal Justice \& Criminology

by

Linde Christine Rush Burkey

May 2012

Larry S. Miller, Ph.D., Chair

John Whitehead, Ph.D.

Michael Braswell, Ph.D.

Keywords: Forensic, Document Examination, Handwriting, Confined Space, Reflex of Avoidance 


\begin{abstract}
Reflex of Avoidance in Spatial Restrictions for Signatures and Handwritten Entries

by

Linde Christine Rush Burkey

Regarding the myriad disputed documents encountered within the science of forensic document examination, questioned handwriting is the most prevalent. This includes the simulation or alteration of and or additions to handwriting and signatures. The current study examined the changes that may occur in writing when given a limited amount of space. Several participants completed a survey wherein writing samples were taken under varying space allowances. These space restrictions were made under differing conditions such as boxed signatures, additions to prewritten material, and alterations to letters and numbers. The results of the study found characteristics of reflex of avoidance in the participants' handwriting. These characteristics included changes in height, width, and letter spacing in accordance to the amount of space provided. The examples of reflex of avoidance defined throughout this study may serve to assist forensic document examiners in the detection of alterations within questioned documents.
\end{abstract}




\section{ACKNOWLEDGEMENTS}

I would first and foremost like to thank my Lord and Savior Jesus Christ for allowing me the opportunity to pursue my graduate education at East Tennessee State University. You have placed such wonderful mentors, colleagues, and peers in my life, and I am so very grateful.

Special thanks to my husband and daughter for your continuous love support throughout this entire process. You both remained patient and encouraged me in spite of the occasions in which I had to forfeit family time in order to focus on my studies. Thank you so much for the many sacrifices you had to make in order for me to pursue my academic career. I could not have been successful in this endeavor without the two of you. I love you both more than you could ever imagine.

Abundant thanks to Dr. Larry Miller for your mentorship over the past several years. I greatly appreciate all of your insight and guidance. You assisted in leading me into a career field in which I have developed such a love and passion, and for that, I am truly grateful. Words cannot express how honored I am to have someone like you in my life. Thank you.

I would also like to thank the rest of the faculty, staff, and graduate students in the Criminal Justice and Criminology Department. To the professors and instructors who have been a true inspiration over the past several years, thank you for challenging and preparing me for a successful future in the field Criminal Justice. I would also like to thank the staff and my fellow graduate students for making this experience such a pleasure. I have enjoyed learning and working with you in this great department.

I love you all. Thank you, from the bottom of my heart. 


\section{CONTENTS}

Page

ABSTRACT …ㄴ...

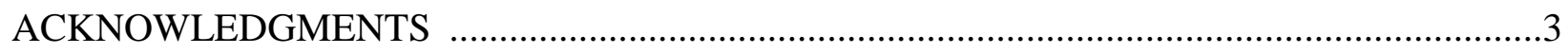

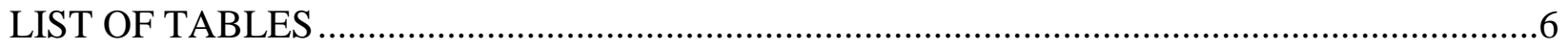

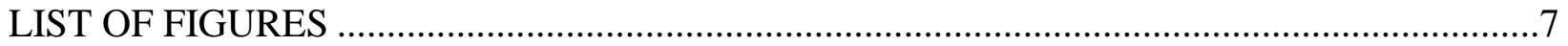

Chapter

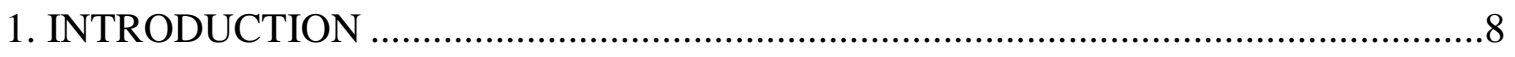

Statement of the Problem.....................................................................................11

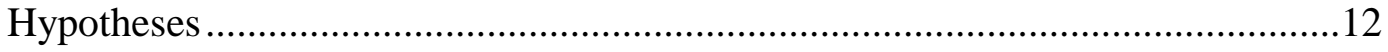

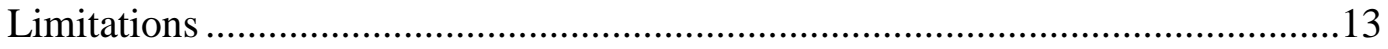

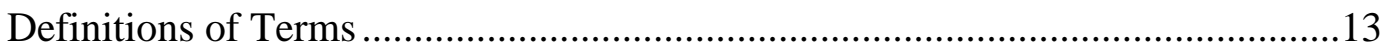

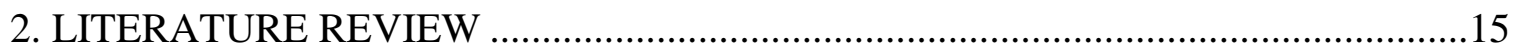

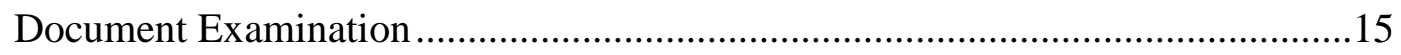

Handwriting and Analysis..............................................................................17

Methodological Practices of Handwriting Analysis...........................................20

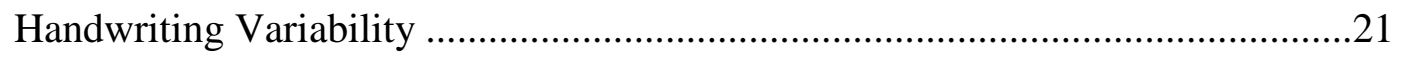


Authentic vs. Nonauthentic Handwriting

Reflex of Avoidance.

Summary 30

3. METHODOLOGY

Introduction

Sample .33

Procedure for Collecting Data. .34

Procedure for Treating Data .34

4. RESULTS .35

Analysis of Data. .35

Summary .45

5. DISCUSSION .47

Findings. .48

Further Research.

REFERENCES 


\section{LIST OF TABLES}

Tables

1. Demographic Characteristics of Respondents................................ 35

2. Length of Signature Based on Unrestricted Size and Restricted Box Size...........37

3. Width of Signatures Based on Unrestricted Size and Restricted Box Size...........38

4. Length of Signatures Based on Unrestricted Size and Restricted Line Size...........38

5. Vertical Spacing of Signatures Based on Unrestricted Size.......................39

6. Crosstabulation of Observed Reflex of Avoidance by Demographic Characteristics of

Sample...............................................................43 


\section{LIST OF FIGURES}

Figures $\quad$ Page

1. Vertical Compression and Reflex of Avoidance.................................39

2. Vertical Compression and Reflex of Avoidance...............................40

3. Vertical and Horizontal Compression Indicating Reflex of Avoidance...............40

4. Vertical and Horizontal Compression Indicating Slight Reflex of Avoidance........40

5. Vertical and Horizontal Compression Indicating Slight Reflex of Avoidance........41

6. Horizontal Compression and the Avoidance of Pre-existing Writing...............42

7. Reflex of Avoidance (left) and No Reflex of Avoidance (right) $\ldots \ldots \ldots \ldots \ldots \ldots \ldots \ldots 43$

8. Reflex of Avoidance in Grade Change Exercise..............................45 


\section{CHAPTER 1}

\section{INTRODUCTION}

Over the past several years forensic sciences have come under severe attack. This includes not only the numerous specialized branches of forensics but also those scientists and experts trained in these disciplines. Multiple crime labs have been investigated for biases, faulty methodological practices, and mishandlings and contaminations of evidence. Many cases that have received recent widespread notoriety have been studied and scrutinized in response to allegations of the possible mishandling of evidence and negligent investigative procedures. The contamination of crime scene evidence was addressed in the O.J. Simpson trial; questions regarding the substantiability of pathological findings (required to assess the cause and manner of death) were raised in the murder cases of Caylee Anthony and NBA player Michael Jordan's father, James Jordan; the reliability of arson investigations were examined in the case of Cameron Willingham - convicted and executed in the deaths of his three children; the empirical validity of document examination was challenged in the murder investigation of JonBenet Ramsey. These are representative cases that have notoriously raised concerns within the public, the courts, and the scientific community regarding the validity and reliability of the forensic sciences and of the testimonies offered by the experts trained in their respective fields.

The reaction to such issues has been the implementation by the courts of more stringent rules concerning expert testimony with the expectation of excluding any testimony containing information deemed to be scientifically unfounded. In 1923 U. S. courts began using the Frye test as a means of admitting or excluding particular types of evidence. Under this test expert testimony was admitted on the basis of the experience, skill, reputation, and credentials of the 
testifying expert under the assumption that evidence could be challenged during cross examination (Frye v. United States, 293 F. 1013, 1014 (D.C. Cir.1923). This allowed the possibility of the admission of erroneous testimony by scientists and experts if discrepancies were not properly addressed in court. In spite of an appearance of leniency in the allowance of unfounded evidence, the Frye test, paradoxically, incurred a reputation for inordinate stringency that often excluded legitimate and potentially decisive evidence. Therefore, in 1975 many state and federal courts abandoned the Frye test in favor of the relevancy standards established by Rule 702 of the Federal Rules of Evidence. This allowed any testimony or evidence into court as long as it was considered more helpful than detrimental to the jury's understanding of the evidence in issue (Kelly \& Lindblom, 2006). Many courts, however, were split over which admissibility standard to use - the Frye test or Rule 702's relevancy standard.

In its 1993 review of Daubert v. Merrell Dow Pharmaceuticals, Inc. the United States Supreme Court eliminated any confusion regarding admissibility standards at the federal level (Kelly \& Lindblom, 2006). In Daubert admissibility standards were redefined to reflect the Federal Rules of Evidence with the judge working as the gatekeeper. Henceforth, to minimize faulty testimony a judge must evaluate a forensic discipline and expert in regards to peer review, error rates, testing procedures, and general acceptance. If the judge does not feel as though these standards are sufficiently achieved, he or she may refuse to allow the testimony or evidence to be introduced into the court. While the Daubert ruling was adopted in the federal court system, several states subsequently deferred to this ruling as well.

Regardless of the changes surrounding expert testimony, controversies remained concerning weaknesses caused by fragmentation within the forensic science community. Collectively, these concerns became the mechanism that prompted the need to further reexamine 
the science of forensics. Therefore, in 2005 Congress commissioned the challenging endeavor of evaluating the numerous forensic science disciplines to the National Academies of Science (NAS). The committee representing the NAS consisted of members from the forensic science community including crime lab directors, medical examiners, coroners, legal experts, and scientists (National Research Council of the National Academies, 2009). The NAS examined specific issues within the forensic sciences including standardization, certification, accreditation, interpretation of evidence, lack of empirical research, and admissibility of evidence (Harralson, 2010). In 2009 the National Research Council publicized its recommendations and presented to Congress a report entitled "Strengthening Forensic Science in the United States: A Path Forward."

The premise of the NAS report determined that forensic sciences had failed to meet the demands of science (Harralson, 2010). Recommendations for improving the validity and reliability of the practices and methods of forensic scientists and experts were addressed. These recommendations included improvements such as the advancement of a standard terminology, research on human observer biases, the establishment of quality assurances, a national code of ethics, the development for tools of measurement, standard education and training programs, and others (National Research Council of the National Academies, 2009). Once released the NAS report was widely publicized and, thereby, indoctrinated attorneys, judges, and scientists on the ever present demands of the forensic science disciplines. While it would take years to implement and enforce the NAS committee's recommendations, the report exposed challenges and limitations within forensics as a science (Harralson, 2010).

Along with other forensic science disciplines, the NAS report specifically addressed the science of forensic document examination and handwriting analysis. The NAS committee 
combined handwriting analysis with the disciplines of tool marks, friction ridge, and footwear and tire print impression analysis into a single group they considered to be "experience based methods of pattern recognition" (National Research Council of the National Academies, 2009). They found that the discipline of forensic document examination was in need of more academically focused training programs, certification and accreditation of both public and private laboratories, and annual document examination proficiency testing. Also suggested by the NAS was a more pragmatic approach to research that would include human biases, error rates, statistical significance of findings, and handwriting examination.

While the NAS report discussed document examination in respect to various aspects of ink identification and sampling issues surrounding ink examination, the main focus was centered on the analysis of handwriting (Harralson, 2010). The committee considered handwriting analysis as a valuable asset to the field of forensic science; however, they found the field to be lacking a sound scientific foundation. The report concluded that the field is in crucial need of research that extends beyond signature comparisons into more problematic areas of handwriting analysis (Harralson, 2010). The current study is responding to the NAS report's request for further study of handwriting examination, more specifically, the implications of handwriting variability and its inclusion therein.

\section{Statement of the Problem}

The purpose of the present study was to investigate the effects of individuals' handwriting when given a limited amount of space and to determine alterations that occur as a result thereof. Such handwriting alterations will be referred to herein as reflex of avoidance. This topic has been essentially untouched by researchers and requires further analysis. This study 
addressed three basic questions. The first question was whether or not there exists a significant difference in lateral and vertical spacing of handwriting and signatures when allotted a limited amount of space. Secondly, the study examined the extent to which individuals avoid writing over preexisting written material. Lastly, the study investigated if demographic characteristics such as age, gender, handedness, and educational level played a role in whether or not one altered his or her handwriting in response to confined space allowances and in avoidance of prewritten material.

\section{Hypotheses}

After a review of the literature and in accordance with the purpose of the present study, the following null hypotheses were formulated:

Ho1: There will be no significant difference in the size of handwriting written in a limited space and handwriting written in an unlimited space.

Ho2: There will be no significant difference in handwriting in an attempt to avoid preexisting writings.

Ho3: There will be no significant difference concerning signs of reflex of avoidance based on demographic characteristics (age, gender, handedness, educational level).

Data were collected to test these hypotheses using a survey administered to East Tennessee State University undergraduate and graduate students. A series of tasks were presented to each participant in order to maximize the multiple variables and scenarios in which a writer may encounter possible reflex of avoidance tendencies. Included in the survey were 
tasks such as writing inside boxes, in-between lines and previous writings, and the changing of the appearance of preexisting letters and numbers.

\section{$\underline{\text { Limitations }}$}

The sample used in this study contained 156 participants from a local university in Northeast Tennessee. The sample included undergraduate and graduate students; therefore, the sample size, as well as the age group and education levels of the sample providers was limited. Data was collected by means of a survey that was designed to portray everyday writing scenarios individuals frequently encounter. However, this process is limited because some scenarios can not be recreated by means of a formatted survey.

\section{Definitions of Terms}

For the purpose of the current study the definitions are as follows:

Analytical methods: "Methods based on the testing of the information in question against the background and knowledge of the subject" (Ellen, 2006, p. 2).

Class characteristics: "aspects, elements, or qualities of writing that situate a person within a group of writers, or that give a written communication a group identity" (Huber \& Headrick, 1999, p. 42).

Compression: the deliberate effort on the part of a writer to reduce length and height of writing in an effort to fit within spatial restrictions of a writing substrate.

Document: "Something that contains information" (Ellen, 2006, p. 2).

Extrinsic: factors within the writers control that may cause writing variations 
Exemplars: "Samples of handwriting, printed text, paper, ink, etc., known to have been produced by a particular individual, machine, or manufacturer" (Kelly \& Lindblom, 2006, p.412).

Handedness: a person's preference for writing with the right or the left hand.

Individual characteristics: exclusive elements that serve to differentiate between members within a group.

Intrinsic: those circumstances beyond the writer's control; they are inherent to the writer and may arise from physical or mental states such as disease, physiological constraints, handedness, or stress.

Reflex of Avoidance: the intentional effort on the part of a writer to remain within set boundaries and/or the avoidance of writing over preexisting written entries or lines on a writing substrate.

Scientific Method: "The study of observed phenomena and the seeking of a correlation between them based on the philosophy that there is order and consistency in the universe" (Ellen, 2006, p. $1)$.

Substrate: writing surface

Tremor: "Shacky, irregular handwriting movements that occur in handwriting or a signature that is slowly executed or written by a person suffering from advanced age, nervousness, or physical/mental infirmities. Also a symptom of forgery, manifested as shaky, irregular strokes caused by unnaturally slow pen movements due to conscious attention to letter forms in deliberate rather than spontaneous writing" (Kelly \& Lindblom, 2006, p.422). 


\section{CHAPTER 2}

\section{LITERATURE REVIEW}

\section{$\underline{\text { Document Examination }}$}

When one thinks of documents, most often sheets of paper with handwritten or computer generated text come to mind. These documents are often of a legal, business, social, or personal nature. However, documents are generally considered to be any form of material containing symbols, marks, or signs that attempt to communicate some type of meaning or message (Kelly \& Lyndblom, 2006). Therefore, besides paper, documents may come in a variety of other forms such as graffiti on walls, lipstick on mirrors, labels on packaging slips, engravings, and stamped impressions. Documents are questioned or disputed when their source or authenticity is uncertain.

A questioned document may be prepared under varying conditions using a multitude of possible materials. While some documents by their very appearance have the potential to raise dispute, others are well prepared and in keeping with their original history. Many questioned documents may involve fraud, theft, counterfeit, impersonation, ransoms, and threats, while others may convey no malicious or criminal objective. Due to the diversity of the conditions in which one may encounter disputed documents, forensic document examination is, therefore, essential to the legal support of law enforcement, attorneys, courts, and civilians in determining the authenticity of such documents.

The examination of questioned documents is defined as the scientific study of the minutiae and rudiments of documents so as to attain their source and/or determine their authenticity (Kelly \& Lindblom, 2006). Forensic document examination is regarded as one of 
the oldest established forensic sciences and is today considered an asset essential to the fields of law and criminal justice.

Forensic document examination as a profession was necessitated by a need within the court system for assistance in the interpretation of evidence specifically involving the examination and handling of documents. It was deemed a "pure forensic science" because it was independently cultivated within the legal system and did not stem from other professions such as engineering, medicine, or dentistry (Hilton, 1982).

Forensic document examiners use the scientific method in conjunction with analytical methods in the process of analysis of questioned documents (Kelly \& Lindblom, 2006). Their work must be performed thoroughly, precisely, and without bias in order to provide accurate, credible testimony to their findings. Forensic document examiners must acquire and maintain a vast breadth of knowledge within the domain of their expertise to allow the ability to readily adapt to varying circumstances that are likely to be encountered in the field. The expanse of their education and familiarity must encompass variances in types of paper, inks, handwriting, print processes, the identification of additions and substitutions, the decoding and interpretation of obliterated and erased materials, the care and handling of documents, and proper courtroom procedure (Kelly \& Lindblom, 2006).

The broad spectrum of disciplines requisite to the science of forensic document examination invites document examiners with widely varied academic backgrounds into the field, to include undergraduate and graduate level degrees in chemistry, biology, psychology, law, criminal justice, and computer science. To establish credibility within the field one must achieve, at minimum, a bachelor's degree from an accredited college or university and acquire 
specialized training that often comes in the form of a 2-year apprenticeship under the tutelage of a qualified forensic document examiner. This training is comprised of the studies of handwriting, forgery detection, print process machines, indentations, paper examination, damage restoration, and physical matching techniques among other proficiencies that may be required for proper analysis. The trainee must also become familiar with the proper and appropriate implementation of lab equipment such as ultraviolet and infrared imaging, microscopes, electrostatic detection equipment, photographic and scanning techniques, and enhancement systems.

\section{Handwriting and Analysis}

The array of knowledge required to establish and maintain credibility within the forensic document examination field is expansive, yet some types of questioned documents are encountered by examiners more often than others - wills, contracts, property deeds, and handwritten records. In fact, document examiners' efforts are focused primarily on handwriting and signatures in more than $70 \%$ of all cases. (Huber \& Headrick, 1999). Therefore, a thorough understanding of the most basic elements of handwriting is paramount to the trained examiner in the pursuit of the most accurate interpretation of documentary evidence.

Historically, handwriting evolved as a way for humans to communicate their thoughts, emotions, and desires to others visually. Some of the earliest writings were developed as drawings found on the walls of caves, known as petroglyphs and or petrograms (Koppenhaver, 2007). Eventually these pictures were adapted into symbols, each becoming a visual representation of sounds or syllables. This evolution continued and led to the eventuality of phonetic alphabets. The Sumerians assigned a specific symbol to each particular sound, thereby developing the first written alphabet, which was spread throughout the known world by the 
Phoenicians. It consisted of 22 letters that were written from right to left with words and sentences separated by periods and slash marks. The Greeks later adopted a form of this alphabet but changed the writing direction from left to right and added vowels. The result was a fixed alphabet consisting of 24 characters. The modern English alphabet, imported into the Americas by European settlers, was the culmination of centuries of additions and variations that were influenced by the Romans and incorporated into the Germanic system. (Koppenhaver, 2007).

Through time advances were made in the development and instruction of writing techniques; writing systems that were implemented to answer the need for consistency that would benefit both the writer and the reader. These methods represented what was considered to be the optimal manner by which an expected formation of letters and language was to be executed relative to the time and location of their development and implementation. Collectively the rote methods and systems that were taught became referred to as copybook styles, copybook forms, style characteristics, and/or national characteristics (Morris, 2000).

Copybook form is defined by Hilton as "the design of letters that is fundamental to a writing system. This term is derived from the old methods of teaching handwriting from a copybook containing engraved script printed on each page for the student to imitate" (Hilton, 1982, p. 18). Harrison describes the resulting characteristics further as being those that are "... taught to the child when learning to write. The style of handwriting that is acquired by the learner is that which is fashionable at that particular time and place. Among the most common and recognizable copybook styles employed in the United States are Zaner - Bloser, D’Nealian, Palmer, and McDougall Little (Morris, 2000). 
While copybook styles of writing are ineffectual in the identification of individual handwriting, they inherently display what are considered to be class characteristics. Class characteristics are "those aspects, elements, or qualities of writing that situate a person within a group of writers, or that give a written communication a group identity" (Huber \& Headrick, 1999, p. 42). Although the determination of a particular copybook style may not assist in the identification of a specific author's writing, it may help to identify the nationality of the writer or the country in which the writer was taught to write (Morris, 2000).

All writing contains examples of class characteristics, but the backbone of handwriting identification is its specific focus on the identification of individual characteristics. Individual characteristics are those exclusive elements that serve to differentiate between members of a group. Hilton describes individual handwriting characteristics as idiosyncratic to a specific writer. He claims it is these idiosyncrasies that constitute the foundation for identification (Hilton, 1982). Certain types of individual characteristics may include unique starting points and stopping points, writing direction, letter construction, and letter connection. Graphic maturity as well as graphic immaturity may also play a large role in the distinctiveness of the writing. It is the scrutiny of these individual characteristics that undergird the document examiner's ability to render a more reliable and valid opinion concerning questioned handwriting samples.

Among the first instances in which the use of document and handwriting examination played an essential role in the outcome of a prominent case, involved French army officer Alfred Dreyfas. Dreyfas was charged and convicted of spying as a result of the use of a forged document wherein the officer allegedly divulged secret French military information to the opposing German forces. Unfortunately, the expert witness, Alphonse Bertillion, whose testimony helped to procure a conviction, was not experienced in the field of handwriting 
analysis. Twelve years later, after much dispute, Alfred Dreyfas was found innocent of the charges and released from prison (Nickell \& Fischer, 1999).

The first and possibly most renowned case in America concerning handwriting analysis involved the Lindbergh baby kidnapping. The ransom notes found at the scene were analyzed by the originator of the FBI lab, Charles Appel. Appel found that the handwriting contained distinctive individual characteristics, including an invented form of an $x$, a simplification of the letter $t$, and an odd formation of the letter $p$. These individual characteristics along with the "rugged manner of execution" helped to convict Bruno Richard Hauptmann of the kidnapping and murder of Charles Lindbergh's son. Although dispute over Hauptmann's conviction continues, Charles Appel's analysis of the handwriting was so pivotal and scientifically sound, it is currently used in the training of document examiners and remains a prime example of the proper methods in which to conduct a case involving questioned documents. (Nickell \& Fischer, 1999).

\section{Methodological Practices of Handwriting Analysis}

There has been considerable controversy over forensic document examiners and their methods of evaluating documents and handwriting. Studies have been conducted to compare the techniques used by forensic document examiners when scrutinizing signatures and techniques employed by individuals outside of the field. A study carried out by Dyer, Found, and Rogers (2008) examined this very notion. The authors' intent was to evaluate the key components of writing on which a trained forensic document examiner focuses attention in comparison to the average layperson. To note the methods of each in evaluating signatures, the study used an eye tracking device - the Tobii 1750 binocular eye system - which followed and recorded eye 
movements and duration of time on which a forensic document examiner or control subject focused specific attention. Nine forensic document examiners and 12 control subjects evaluated 32 questioned signatures. While the results concluded that the forensic document examiner as well as the nonspecialist focused on similar writing features in order to render a decision, the expertise of the document examiner was found to emanate from the manner of his or her assimilation and cognitive processing of information. It was also determined that document examiners not only focused on significant individual writing features but other minutia present within the signature likely to be ignored by the lay person (Dyer et al., 2008).

The results of this study have helped to underpin the methods presently used in the examination of questioned documents. Due to the knowledge and expertise possessed by document examiners, they are not only imperative to the proper assessment of questioned documents but are also essential to the development and establishment of better educated processes by which questioned writing is to be examined and informed opinions rendered. Therefore, through their skills the experts within the field of forensic document examination make knowledgeable, legitimate contributions to the various criminal, civil, and social fields.

\section{Handwriting Variability}

Handwriting is considered to be an acquired skill, most frequently referred to as a complex perceptual motor task (Huber \& Headrick, 1999; Zaki \& Ibraheim, 1983). Handwriting, like fingerprints, is unique to each individual, making it invaluable as an identifying tool. However, genuine writing executed by the same writer does vary to some extent. Albert S. Osborn, recognized as the father of document examination, explains that such variation occurs because the "arm, hands, and fingers do not constitute an absolutely accurate 
reproducing machine" (Osborn, 1973, p. 205). He further details his premise that variations in authentic writing most often occur in superficial sections, in size and proportion, as well as in the extent of care given to the written act. Therefore, as with speech, which may be communicated either softly or loudly and with or without the use of proper diction, writing by the same individual may be executed in either a careful or a careless manner. Consequently, the writing processes accompanied by individual variations become fixed habits acquired by the individual after several replications of the same act. (Osborn, 1973). Although the act of writing, as an acquired skill, is performed subconsciously and becomes a settled action over time, occasional variables may have more drastic effects and cause extreme changes in one's writing. Such variables are classified as and occur as the result of extrinsic and intrinsic conditions.

Extrinsic factors may be considered circumstantial and well within the control of the writer. Examples of variables that may affect alterations to one's handwriting include lighting, choice of writing instrument, type of writing surface, temperature, and myriad other possible conditions. Another extrinsic variable is the notion that, on occasion, the alteration of writing is purposeful and adopted by the author as "a product of a personality change produced by a problem of the time" (Huber \& Headrick, 1999, p. 227). The result of such a variable may be manifested as an imitation by the author of the writing style of another such as a teacher or a peer. Ordinarily, however, these factors can be easily controlled by the writer by simply turning on a light source, adjusting a thermostat, choosing an alternate writing instrument, or correcting his or her writing position.

Multiple studies have been performed to examine the effects of extrinsic variables on handwriting variations, the majority of which focused on differences found to occur when using differing writing surfaces. One such study was conducted by Kelly (1978) and involved unusual 
writing surfaces. Test subjects were asked to write upon the surface of an inflated balloon, and the resulting writing variances were studied. Kelly determined that irregular substrates interfered with the writing instrument and thereby resulted in writing irregularities that would not have occurred under normal writing conditions. It was observed that indicators of handwriting written on irregular writing surfaces included abrupt directional changes, larger upper and lower loops and swirls, as well as tremor effects. DeAngelis (1997) conducted a similar study aimed at examining the effects of writing surfaces on handwriting, the results of which showed abnormal substrates affected the overall appearance and line quality of an author's writing including abrupt interruptions, unevenness, and evidence of skips by the writing instrument.

Signatures written on smooth surfaces and those written on a variety of uneven surfaces were also examined and compared by Herkt, Boot, and Walsh (1999). Their investigation revealed results similar to those of the aforementioned studies. In support of the Kelly and DeAngelis studies, line quality inconsistencies were found to result from writing tasks performed on irregular writing surfaces. They also ascertained that in conjunction with the substrate and other intrinsic and extrinsic variables such as inebriation, fatigue, and uncomfortable positioning played a key role in the overall quality of handwriting.

One of the most concentrated studies concerning the effects of extrinsic variables on handwriting quality was conducted by Miller and Harralson (2006). The authors of the study focused not only on substrates but also on the physical position of the writer. Each test subject was asked to sign the name of George Washington using writing surfaces including brick, concrete, leather, wood, and fabric. They were also asked to perform the writing tasks while standing, kneeling, and sitting. The results of the study were similar to those of the preceding 
studies. It was determined that the quality of handwriting was greatly diminished by the impact of extrinsic factors such as substrate and positioning (Miller \& Harralson, 2006).

Intrinsic factors are defined as those circumstances beyond the writer's control; they are inherent to the writer and may arise from physical or mental states, such as disease, physiological constraints, handedness, or stress. (Huber \& Headrick, 1999; Miller \& Harrlson, 2006). A study conducted by Wellingham-Jones (1991) of 23 Multiple Sclerosis (MS) patients, found that MS had obvious and dire effects on the overall quality of handwriting. The writing of individuals afflicted with MS exhibited a lack of fluency and a decrease in lateral expansion and speed accompanied by distortions and tremor characteristics. (Huber \& Headrick, 1999).

The practical implications of the findings of these studies suggest that intrinsic variables must first be recognized by the forensic document examiner. Subsequently, all available research should be applied to the evaluation of any handwriting or signature samples. The impacts of handedness, physical and mental ailments, and handicaps must always be considered to achieve full understanding of the possible cause(s) of variations within writing. It is only through astute attention to detail gained by the assimilation of existing research pertinent to the field that the examiner will possess the potential to accurately identify forged or non-authentic writing.

The findings of the several studies previously cited indicate that aberrations in individual handwriting may occur under multitudinous conditions, both extrinsic and intrinsic.

Consequently, such formative aspects possess the potential to create variations in handwriting that further complicate the field of document examination, wherein the examiner regularly encounters the task of determining whether or not a writing sample is authentic. Although 
considerable research has been conducted regarding derivations of handwriting variability, numerous aspects remain untouched by empirical investigation.

\section{Authentic vs. Nonauthentic Handwriting}

The principle focus of the forensic document examiner is the examination of handwriting; therefore, knowledge and expertise must extend beyond those variances deemed inherent to a specified author. Under many circumstances forensic document examiners must compare writings of an allegedly fraudulent nature. This may encompass forged or disguised writing and signatures on wills, checks, suicide notes, diaries, address books, contracts, prescriptions, medical records, and other personal or legal documents. Document examiners are frequently confronted, especially during the delivery of testimony as an expert witness in court, concerning their ability to distinguish between authentic and nonauthentic handwriting samples. The amount of research into the abilities of forensic document examiners to definitively identify writing samples as being disguised and/or forged is limited, despite the fact that it is a subject that is highly scrutinized and is commonly addressed in criminal and civil cases.

Authors Dyer et al. (2008) recognized the need for research involving this particular subject. The article, entitled An Insight into Forensic Document Examiner Expertise for Discriminating between Forged and Disguised Signatures, compared the identification abilities of 8 forensic document examiners to those of 12 control subjects. Each participant viewed a series of signatures and subsequently rendered his or her opinion as to whether each example was disguised or forged or uncertain regarding its authenticity. The study found that trained forensic document examiners had a considerably lower error rate, at $28.2 \%$, when compared to the control group, at $71.8 \%$ (Dyer et al., 2008). 
Another study conducted by Bird, Found, and Rogers (2011) found correlative results. In a method similar to that employed by the Dyer study, the authors compared the opinions of forensic document examiners to those of lay persons as the two groups distinguished between 140 pairs of natural and disguised signatures. The results of this study determined that, although the document examiners' error rate was only $3.38 \%$, in contrast to that of the lay persons at $11.43 \%$, the document examiners were more conservative in their expression of a definitive opinion. It was shown the likelihood of the document examiners to offer an inconclusive opinion exceeded twice that of the lay persons, reflecting $23.05 \%$ and $8.43 \%$ respectively. Therefore, it became apparent that through an intensive educational process, forensic document examiners have been taught to apply constraint when offering an opinion, whereas the lay person is more likely to venture a guess (Bird et al., 2011).

Forensic document examiners are frequently confronted by the difficult task of examining questioned documents involving the writings or signatures of individuals affected by various forms of neurological disorders. Specific maladies that directly impact the involuntary movements of the afflicted individual are known as tremor disorders and have a significant influence on the examiner's ability to provide accurate forensic verification of handwriting. Tremor disorders are often marked by involuntary rhythmic muscle movements, which can manifest in the arms, legs, face, head, voice, and trunk, although most affect the hands of the afflicted individual. The resulting influences can be divided into three categories: resting (Parkinsonian), postural (essential and asterixis), and action or intentional (essential and cerebellar). A study conducted by Harralson (2010) entitled Forensic Handwriting Examination of Motor Disorders and Forgery suggests that certain types of tremors, specifically essential tremors, are more difficult to forge than others. Therefore, the examiner is confronted with a 
unique challenge when attempting to formulate an opinion regarding the writing of those individuals exhibiting such characteristics, especially documents associated with end of life decisions such as last wills and testaments composed by members of the aging population. (Shraberg, 2011).

Both Miller (1987) and Walton (1997) examined the opinions of forensic document examiners in relation to the disguised and forged signatures of those afflicted with specific yet differing tremor disorders. Miller investigated and examined signatures and writing executed by individuals affected by arthritis, whereas Walton studied the writings of those afflicted with Parkinson's disease. Both debilitating ailments were found to impair writing in similar manners: the exhibition of tremor characteristics and a general lack of fluency. After completing the initial examination of the authentic samples, a control group made up of healthy individuals produced intentional forgeries of the impaired signatures that were then examined and compared to the authentic examples by trained document examiners. Both studies revealed the difficulties encountered when attempting to distinguish between authentic signatures created by individuals afflicted by tremor disorders and those contrived by the intentional fraudulent simulation of the same characteristics. However, both Miller and Walton arrived at the conclusion that an informed and accurate determination of authenticity could be reached through the collection of a sufficient number of exemplars from known writings from within the proximal frame of time as that of the questioned document.

Although it may be difficult for forensic document examiners to distinguish between some types of forged or disguised handwriting and signatures, the rendering of an inconclusive or erroneous determination is rare. Leung, Cheng, Fung, and Poon (1993) found that that those who simulate signatures and handwriting do so by focusing on a few key features while 
neglecting the finer, more delicate features of the writing. These findings may be employed to equip the document examiner with a distinct advantage: in addition to the difficulty of forging a signature, by neglecting these specific intricacies within the authentic writing, the inherent characteristics of the actual writer will be inadvertently revealed, thereby notifying the educated document examiner of the possibility of a nonauthentic piece of writing.

\section{$\underline{\text { Reflex of Avoidance }}$}

The current study employs the fundamentals of handwriting analysis including methodology, variability, and authentication in the investigation of the handwriting phenomenon referred to as reflex of avoidance. Reflex of avoidance is defined as the intentional effort on the part of a writer to remain within set boundaries and/or the avoidance of the overwriting of preexisting entries or lines on a writing substrate. This action may occur in handwritten signatures as well as insertions of both an authentic and nonauthentic (fraudulent) nature. Forensic document examiners may encounter indications of reflex of avoidance in innumerable documents including medical records, dated entries on calendars, account ledgers,

pharmaceutical records, prescriptions, banking instruments, checks, and diaries. Knowledge of the propensity of the occurrence of this phenomenon is essential to the field of forensic document examination to provide examiners with signs of reflex of avoidance that may assist in the accurate identification of nonauthentic versus authentic handwritten additions and/or alterations.

Although particular aspects of reflex of avoidance have been included in previous studies, no published research exists regarding the phenomenon as an independent and unique entity. One feature of reflex of avoidance was included in a study conducted by Morton (1980), 
in conjunction with the United States Postal Service, examining the effects of crowding on the appearance of a signature. Eleven volunteers ranging in age from their mid 20s to 50s provided five sample signatures on a sheet of paper. The sample signatures were measured both vertically and horizontally, creating the baseline for the study. Morton then had the volunteers provide signatures with restrictions in the allowance of vertical and lateral space. The study found that when given a limited amount of space vertically and horizontally individuals reduced the space between words and letters while narrowing each individual letter. The participants also reduced the overall size of their signatures resulting in miniaturized versions of the originals. A key element of the study results was the inadvertent discovery that while crowding and reduction was found in all of the signatures fluency was not lost. While this study focused on only 11 subjects, the results were apparent and consistent among all samples (Morton, 1980).

Reflex of avoidance may also be apparent in everyday application of course of business signatures. The current technology allows signatures to be written under a variety of conditions. With increasing frequency, signatures are acquired by means of electronic methods such as electronic pin signatures, computer mouse signatures, and electronic pens and notepads. When purchasing items with a credit card, signatures are most often written on electronic notepads; police officers use electronic signatures in the process of administering tickets; many legal organizations and corporate business institutions, especially insurance companies, employ electronic signatures in the verification of contracts and documents. While this advancement in the use of technology may be considered convenient to the individual providing his or her signature, the writing space provided is often quite limited. Therefore, signatures collected under these circumstances may exhibit specific characteristics of reflex of avoidance. 
A study conducted by Harralson, Tuelings, and Miller (2011) was designed to examine variations that may result from the implementation of electronic collection methods. Sixteen participants signed their names using a digital ball point pen that recorded signatures that would represent the control or comparison samples. These signatures were written with no horizontal or vertical constraints. The test subjects then signed their names within a box provided on a digital tablet. The result of the study revealed that there was a significant difference between the control signatures and those written in the confined space on the digital tablet. While the signatures did not portray significant changes vertically, obvious alterations occurred in horizontal configuration. In the attempt to fit their signature within the designated electronic signature writing box, most participants condensed horizontal spacing to reduce overall length. Some subjects chose to avoid contracting their signature and chose instead to reduce length by replacing full names with initials. As stated, however, very little or no alteration was observed regarding vertical alignment in comparison to the original, unrestricted signatures (Harralson et al., 2011). The results of this study as well as the findings in the Morton study provide information essential to the identification of key components of handwriting alteration that may emerge as a manifestation of reflex of avoidance.

\section{$\underline{\text { Summary }}$}

The National Academy of Sciences has publicly urged researchers to provide further studies concerning all elements of the field of forensic document examination and handwriting analysis. Although moderate study has been conducted in the identification of specific ink and paper types or indentions, these pertain to more universal characteristics of a document. Investigation into the particulars of handwriting analysis, especially in relation to the cause and effect of intrinsic and extrinsic factors on writing variations, has received very limited if any 
attention by researchers. This becomes disconcerting when considering the fact that the majority of the forensic document examiner's time is spent predominantly focused not on the material construction of a document but rather on the examination and analysis of questioned handwriting composed thereon. The NAS report claims:

The scientific basis for handwriting comparisons needs to be strengthened. Recent studies have increased our understanding of the individuality and consistency handwriting and computer studies and suggest that there may be a scientific basis for handwriting comparison, at least in the absence of intentional obfuscation or forgery. Although there has been only limited research to quantify the reliability and replicability of the practices used by trained document examiners, the committee agrees that there may be some value in handwriting analysis. (National Research Council of the National Academies, 2009).

Although NAS perceives and assigns a real value to handwriting analysis, reservations remain concerning the discipline's ability to maintain validity within the scientific community. As a result, the scientific foundation of handwriting analysis requires empirical fortification that can and will only be realized through innovative, compelling, and authoritative research.

Continuing research is essential to providing and maintaining credibility, reliability, and validity within any scientifically based field. The handwriting phenomenon identified as reflex of avoidance is a regularly occurring characteristic tendency in writing that has remained virtually unrecognized and untouched by previous research. Therefore, this is one of many aspects of handwriting analysis that needs attention by fellow document examiners in order to assist in the recognition and identification of nonauthentic writings. The current study is in response to the NAS report's request for further examination of possible variations that may affect fluctuations in handwriting at both interpersonal and intrapersonal levels. 
Due to the plethora of conditions under which reflex of avoidance may occur, further exploration of the subject and its possible analytical implications within the field is imperative. Therefore, the current study investigates and compares the process by which an author may alter his or her handwriting when writing space is restricted as well the modifications that are likely to be made to one's normal writing when an attempt is being made to avoid preexisting writings. The recognition and study of these alterations under both authentic and nonauthentic (fraudulent) conditions will assist those working in the field of handwriting analysis with the detection of and the rendering of appropriate opinions and conclusions regarding the nature of this handwriting phenomenon. The current research will advance the field of forensic document examination and provide greater validity and reliability of forensic document examiners within the scientific and legal communities by providing key research into components of writing which portrays authentic and nonauthentic examples of reflex of avoidance. 


\section{CHAPTER 3}

\section{METHODOLOGY}

\section{$\underline{\text { Introduction }}$}

The purpose of this study was to investigate the propensities and signs of reflex of avoidance. In doing so, handwritten entries and signatures written without spatial limitations and those written in confined spaces were examined and measured in an attempt to find a significant difference. Alongside space restrictions, assessments were made to see if writers attempted to avoid writing over prewritten material and if so, the possible variation of handwriting under these conditions. Signs of reflex of avoidance were also examined in relation to demographic characteristics to see if age, gender, handedness, or educational level played a role in whether or not one altered his or her handwriting in response to confined space allowances. Three hypotheses were purposed. The first null hypothesis was: there will be no significant difference in the size of handwriting written in a limited space and handwriting written in an unlimited space. The second null hypothesis stated: there will be no significant difference in handwriting in an attempt to avoid preexisting writings. The third null hypothesis was: there will be no significant difference concerning signs of reflex of avoidance based on demographic characteristics (age, gender, handedness, educational level).

\section{$\underline{\text { Sample }}$}

The population for the current study included undergraduate and graduate students enrolled in criminal justice classes at East Tennessee State University. The convenience sample was taken from six different classes providing a sample size of 156. Permission was obtained 
from the instructors to administer the survey instrument during regular class time. Students were advised their participation was fully voluntary and anonymous.

\section{Procedure for Collecting Data}

A self-administered survey (see Appendix) was used as the instrument for the data collection tool in the current study. The survey was four pages long and contained 28 separate writing requests. The survey included the independent variables along with the essential dependant variables. The independent variables in this study included, limited space allowances, preexisting written material, and demographic characteristics (age, gender, handedness, educational level). Limited space exercises were measured at a ratio level, while observable efforts to avoid writing over pre-existing lines and demographic variables were measured at the nominal level. The dependent variables included writing alterations made by the writer both laterally and vertically (compression) and were measured at the ratio level.

\section{Procedure for Treating Data}

Analysis and comparison of the survey instrument was the first step in examining the data. Each survey instrument was evaluated to determine if the respondent had followed directions in filling out the survey and that the survey was usable for analysis. Demographic characteristics and nominally measured variables were examined and compared using a frequency distribution and contingency table analysis. Chi-Square and Phi or Cramer's V were used to test for significant relationships with these nominal variables. Analysis of Variance (ANOVA) and the Tukey HSD (Honestly Significant Differences) post-hoc test were used to test for significant mean differences for ratio level measured variables. 


\section{CHAPTER 4}

\section{RESULTS}

\section{$\underline{\text { Analysis of Data }}$}

The sample of university students participating in the present study yielded 156 surveys. Of the 156 subject responses, 112 were found to be adequate for the present study. The 44 responses not selected were determined to be inappropriate due to failure on the part of the respondent to follow directions or to fully complete the instrument and/or the questionnaire. As the data in Table 1 indicate, the remaining 112 respondents consisted of 68 males and 44 females all ranging in age from 18 to 65 years. Educational levels of the respondents ranged from some college (first year freshmen) to graduate students (master degree students). Respondents were predominately right-handed $(\mathrm{n}=91)$ and none suffered from any anomaly that could affect their handwriting skills (i.e., medications and physical conditions).

Table 1

Demographic Characteristics of Respondents

Attribute

Gender

Male Female

Total

Age

18-20

21-30

Over 30

Total

Handedness

Right

\section{$\mathrm{N}$}

68

44

112

51

49

12

112

91
$\%$

61.0

39.0

100.0
46.0

44.0

10.0

100.0 
Table 1 (continued)

$\begin{array}{lrr}\text { Left } & 21 & 19.0\end{array}$

$\begin{array}{lll}\text { Total } & 112 & 100.0\end{array}$

Educational Level

$\begin{array}{llr}\text { Some College } & 94 & 84.0\end{array}$

Graduate School $\quad 18 \quad 16.0$

Total $112 \quad 100.0$

The first research question examined if significant differences occurred with handwritten signatures within a limited space. Respondents were asked to write the name Thomas Jefferson in an unrestricted spatial area on the instrument (Signature 1), the name Thomas Jefferson within a large box area measuring 3.125 inches by 0.438 inches (Signature 2) and, the name Thomas Jefferson within a small box area measuring 0.688 inches by 0.313 inches (Signature 3). Respondents were also asked to write the name Thomas Jefferson on a long line measuring 4.125 inches (Signature 4) and on a shorter line measuring 1.375 inches (Signature 5). To determine vertical spacing changes in handwriting, respondents were asked to sign the name Thomas Jefferson on three lines vertically spaced 0.375 inches apart and 2.563 inches in length (Signature 6). Each signature was measured by overall length and overall height in inches. The results of the signature measurements exposed if the writer horizontally and/or vertically compressed his or her writing to compensate for the spatial restriction compared with the signatures written in an unrestricted space.

The first analysis compared measurements of the unrestricted signature with signatures written in larger and smaller boxes. As the data in Tables 2 and 3 depict, there were significant differences found in both length and width of the signatures with the ANOVA statistic $(\mathrm{F}=$ 
86.31, $\mathrm{p}<.001$ for length and $\mathrm{F}=37.75, \mathrm{p}<.001$ for width). Tukey post-hoc tests revealed that there were no significant differences between the unrestricted signature measurements in length $(\mathrm{p}=.703)$ with the larger box but did find significant differences in both height and length with the smaller box $(\mathrm{p}<.001$ for both height and length).

Tables 4 and 5 depict the ANOVA findings with length and vertical spacing of the lines in comparison to the unrestricted signing of the name Thomas Jefferson. Length of the available line was found to be significant with ANOVA $(\mathrm{F}=16.34, \mathrm{p}<.001)$. The Tukey post-hoc test revealed that the shorter line showed significant horizontal compression as compared to the unrestricted signature and the signature on the longer line $(p<.01)$. Surprisingly, the height of the signatures on the three lines with more narrow vertical spacing was not significantly different from the height on the three lines with wider vertical spacing $(F=.081, p=.970)$. It may be that the spacing between the more narrow lined entries was wide enough to accommodate the efforts of the writers (see Figures 1-5).

Analysis of Variance Results for Length and Width of Signatures (Tables 2-5)

Table 2

Length of Signature Based on Unrestricted Size and Restricted Box Size

\begin{tabular}{lcrccc}
\hline & Sum of Squares & \multicolumn{1}{c}{ df } & Mean Square & F & Sig \\
Between Groups & 82.450 & 2 & 41.225 & 86.306 & .000 \\
Within Groups & 35.825 & 110 & .478 & & \\
Total & 118.275 & 112 & &
\end{tabular}

Multiple Comparisons (Tukey HSD) Results

(I) Signature (J) Signature Mean Difference Std. Error Sig.

$\begin{array}{lllll}1 & 2 & .19 & .192 & .703\end{array}$


Table 2 (contined)

\begin{tabular}{lllll} 
& 3 & 2.25 & .192 & .000 \\
2 & 3 & 2.20 & .192 & .000 \\
\hline
\end{tabular}

Table 3

Width of Signatures Based on Unrestricted Size and Restricted Box Size

\begin{tabular}{llrlll}
\hline & Sum of Squares & df & Mean Square & F & Sig \\
Between Groups & 4.185 & 2 & 2.092 & 37.749 & .000 \\
Within Groups & 4.157 & 110 & .055 & & \\
Total & 8.342 & 112 & & &
\end{tabular}

Multiple Comparisons (Tukey HSD) Results

\begin{tabular}{lllll} 
(I) Signature & (J) Signature & Mean Difference & Std. Error & Sig. \\
1 & 2 & .19 & .065 & .014 \\
& 3 & .56 & .065 & .000 \\
2 & 3 & .37 & .065 & .000 \\
\hline
\end{tabular}

Table 4

Length of Signatures Based on Unrestricted Size and Restricted Line Size

\begin{tabular}{llrccc}
\hline & Sum of Squares & df & Mean Square & F & Sig \\
Between Groups & 30.933 & 3 & 10.311 & 16.340 & .000 \\
Within Groups & 61.327 & 109 & .055 & & \\
Total & 92.321 & 112 & & &
\end{tabular}

Multiple Comparisons (Tukey HSD) Results

$\begin{array}{lllll}\text { (I) Signature } & \text { (J) Signature } & \text { Mean Difference } & \text { Std. Error } & \text { Sig. } \\ 1 & 4 & .09 & .223 & .979 \\ & 5 & 1.32 & .223 & .000 \\ & 6 & .90 & .223 & .001\end{array}$


Table 4 (continued)

\begin{tabular}{rrrrr}
4 & 5 & 1.23 & .225 & .000 \\
& 6 & .81 & .225 & .003 \\
5 & 6 & -.42 & .225 & .241 \\
\hline
\end{tabular}

Table 5

Vertical Spacing of Signatures Based on Unrestricted Size and Restricted Line Size

\begin{tabular}{llrllc}
\hline & Sum of Squares & $\mathrm{df}$ & Mean Square & $\mathrm{F}$ & Sig \\
Between Groups & .016 & 3 & .005 & .081 & .970 \\
Within Groups & 6.557 & 109 & .068 & & \\
Total & 6.573 & 112 & & & \\
\hline
\end{tabular}

3. Thomas Jeffereron

2. In the box below, sign the name Thomas Jefferson.

$$
\text { Thomas Jefferson }
$$

3. In the box below, sign the name Thomas Jefferson.

Thomas Jefferce

Figure 1. Vertical Compression and Reflex of Avoidance 
In the box below, sign the name Thomas Jefferson.

$$
\text { Thmas fiffusm }
$$

In the box below, sign the name Thomas Jefferson.

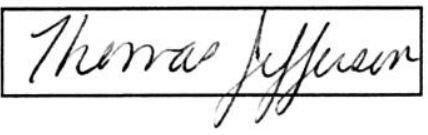

Figure 2. Vertical Compression and Reflex of Avoidance

in the oox deiow, sign me name 1 nomas Jemerson.

Thomas fefferson

In the box below, sign the name Thomas Jefferson.

Thomes fefferson

Figure 3. Vertical and Horizontal Compression Indicating Reflex of Avoidance

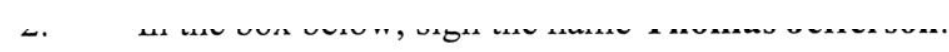

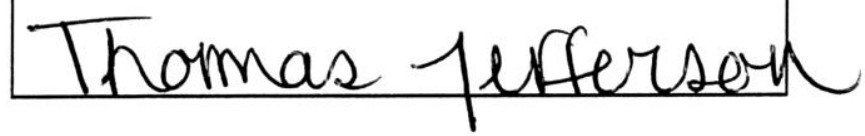

3. In the box below, sign the name Thomas Jefferson.

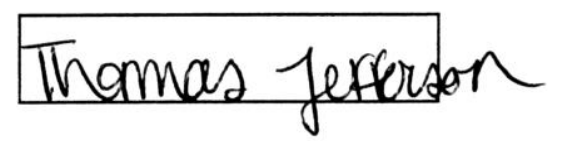

Figure 4. Vertical and Horizontal Compression Indicating Slight Reflex of Avoidance 


\section{Thomas ferfersen}

2.Thrmas ferterson

3.Themas Jesterson

On the lines below, sign the name Thomas Jefferson

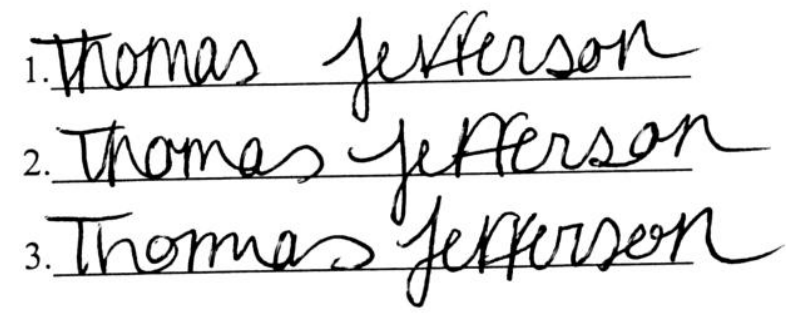

Figure 5. Vertical and Horizontal Compression Indicating Slight Reflex of Avoidance

The most obvious reflex of avoidance was depicted in sentence insertions. Respondents were asked to write three to four sentences on the instrument and then go back and add a sentence between two of those sentences. Nearly all (98\%) respondents showed some degree of vertical compression. Most of the respondents (78\%) attempted to avoid writing through existing handwritten lines by either bending the writing line or altering upward and downward strokes. This was true even when they were not told to try and make the insertion look as though it was not inserted. Figure 6 illustrate these findings. 


\section{December 14-10:00 a.m. Appointment with John Doe. December $15-11: 00$ a.m. Final walk through of property with J 0 hn Doe. December 16 - 9:30 a.m. Closing at bank on Doe property.}
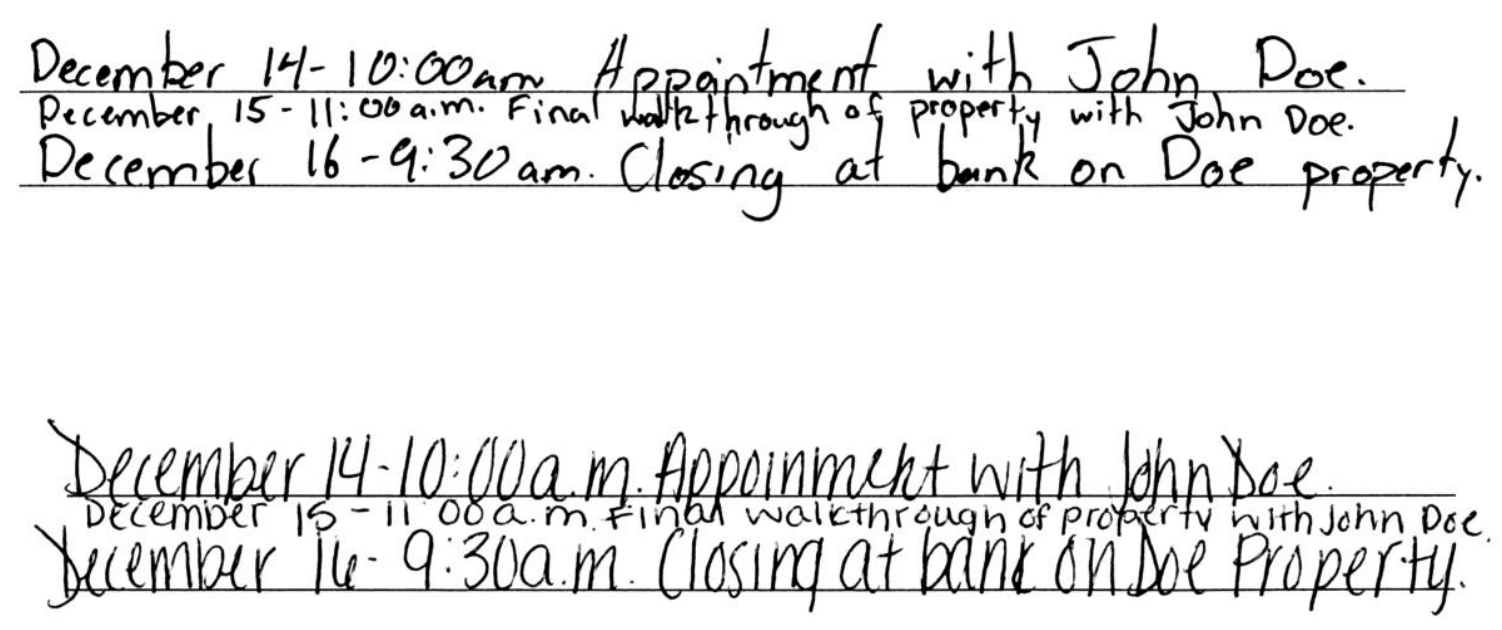

Figure 6. Horizontal Compression and Avoidance of Pre-existing Writing

Numerical insertions showed considerable variation among the respondents. The subjects were asked to change the number 10 to 9,510 on a line and to change the number 10 to 6,410 in a box. A slight majority of the subjects (56\%) attempted to keep the numbers on the line while the remaining respondents paid little or no attention to the line (see Figure 7). Interestingly, most of those making an attempt to keep the numbers on the line were female. Numbers within boxes showed more attempts by respondents to write within the box. A larger majority of the respondents (72\%) attempted to keep the inserted numbers in the boxes as opposed to lines (see Figure 7). 
12. Add a 9 and a 5 to the nu

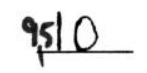

13. Add a 6 and a 4 to the nu

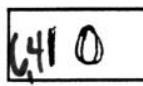

12. Add a 9 and a 5 to $t]$

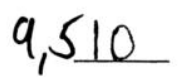

13. Add a 6 and a 4 to tl

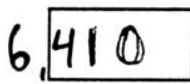

Figure 7. Reflex of Avoidance (left) and No Reflex of Avoidance (right)

In order to answer the research question regarding whether demographic characteristics (age, gender, handedness, educational level) had any influence over whether or not respondents used a reflex of avoidance in their written entries, contingency table analyses were conducted. As the data in Table 6 illustrate, there were no significant differences found with respect to age, gender, handedness, or educational level. However, it was noted that females had a tendency to use reflex of avoidance more frequently than males. It was also noted based on observation that males appeared to be more skilled at making insertions less noticeable than females.

Table 6

Crosstabulation of Observed Reflex of Avoidance by Demographic Characteristics of Sample

$\begin{array}{llll}\text { Age } & 18-20 & 21-30 & \text { Over } 30\end{array}$

$\begin{array}{ccccccccc}\text { Reflex of Avoidance } & \mathrm{N} & \% & \mathrm{~N} & \% & \mathrm{~N} & \% & \mathrm{~N} & \% \\ \text { Yes } & 30 & 58.8 & 39 & 79.6 & 9 & 75.0 & 78 & 69.6 \\ \text { No } & 21 & 41.2 & 10 & 20.4 & 3 & 25.0 & 34 & 30.4 \\ \text { Total } & 51 & 100.0 & 49 & 100.0 & 12 & 100.0 & 112 & 100.0\end{array}$

\begin{tabular}{lllllll}
\multicolumn{2}{c}{ Chi - Square $=4.698$} & \multicolumn{2}{l}{ 2 Degrees of Freedom } & $\mathrm{p}>.05$ & \\
\hline \multirow{2}{*}{ Gender } & Male & Female & \multicolumn{2}{c}{ Total } \\
Reflex of Avoidance & $\mathrm{N}$ & $\%$ & $\mathrm{~N}$ & $\%$ & $\mathrm{~N}$ & $\%$ \\
Yes & 43 & 63.2 & 35 & 79.5 & 78 & 69.6
\end{tabular}


Table 6 (continued)

$\begin{array}{lrrrrrr}\text { No } & 25 & 36.8 & 9 & 20.5 & 34 & 30.4 \\ \text { Total } & 68 & 100.0 & 44 & 100.0 & 112 & 100.0\end{array}$

\begin{tabular}{cllllll}
\multicolumn{2}{c}{ Chi-Square $=3.42$} & 1Degree of Freedom & $\mathrm{p}>.05$ & \multicolumn{2}{l}{ Total } \\
\hline Handedness & \multicolumn{2}{l}{ Right } & \multicolumn{2}{l}{ Left } & N & $\%$ \\
Reflex of Avoidance & $\mathrm{N}$ & $\%$ & $\mathrm{~N}$ & $\%$ & 78 & 69.6 \\
Yes & 62 & 68.1 & 16 & 76.2 & 34 & 30.4 \\
No & 27 & 31.9 & 7 & 23.8 & 112 & 100.0 \\
Total & 91 & 100.0 & 21 & 100.0 &
\end{tabular}

\begin{tabular}{cllllll}
\multicolumn{1}{c}{ Chi-Square $=.018$} & 1Degree of Freedom & $\mathrm{p}>.05$ & \multicolumn{2}{l}{ Total } \\
\hline Education Level & College & Graduate Student & & \\
Reflex of Avoidance & $\mathrm{N}$ & $\%$ & $\mathrm{~N}$ & $\%$ & $\mathrm{~N}$ & $\%$ \\
Yes & 60 & 73.4 & 9 & 50.0 & 78 & 69.6 \\
No & 25 & 26.6 & 9 & 50.0 & 34 & 30.4 \\
Total & 94 & 100.0 & 18 & 100.0 & 112 & 100.0 \\
& & & & & & \\
Chi-Square $=3.83$ & 1Degree of Freedom & $\mathrm{p}>.05$ & & \\
& & & & &
\end{tabular}

Perhaps the most interesting finding in the present study was the grade change exercise respondents were asked to perform on the survey instrument. Subjects were asked to change a graded answer on a simulated test answer sheet. The letter A was written in pencil and marked over using a red ink pen. The respondents were asked to change the letter A to the letter B as if they were attempting to cheat on the test and claim an error in grading on the part of the instructor. Given that the respondents were all students, the exercise may have been familiar to 
many of them. Most of the respondents erased the letter A and inserted the letter B using pencils provided to them. Most surprising was the degree of reflex of avoidance the respondents displayed. A majority of the respondents (68\%) attempted to avoid writing across the already present red ink mark. Contingency table analysis with Chi-Square indicated there were no significant differences for any of the demographic characteristics measured (age, gender, handedness, educational level). Several respondents used a portion of the letter A to form the letter B in order to avoid writing over the red ink mark. Many respondents simply wrote as close to the red mark without going over it or changed to a lighter pressure with the pencil while crossing the red line (see Figure 8).
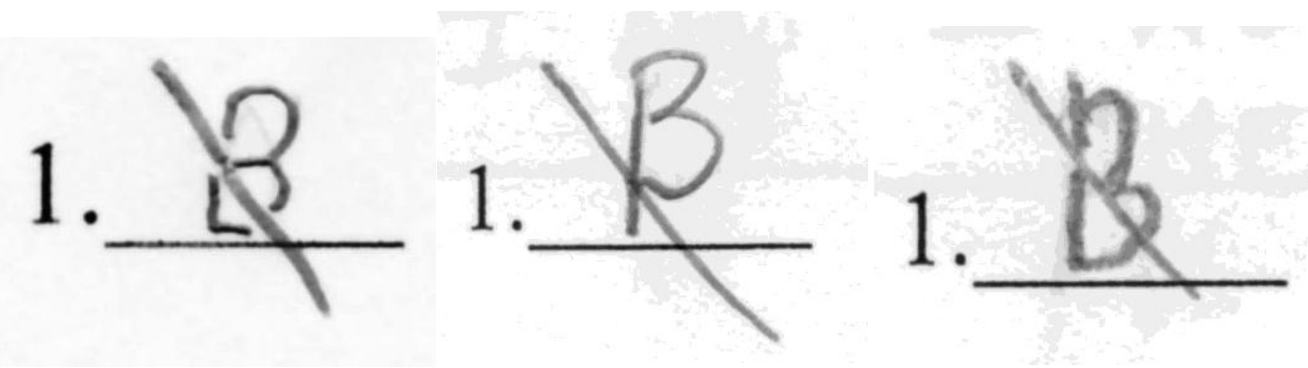

Figure 8. Reflex of Avoidance in Grade Change Exercise

\section{$\underline{\text { Summary }}$}

There were three primary hypotheses under examination for the present study. The first null hypothesis indicated there would be no significant difference between the size and appearance of handwritten entries based on spatial restrictions. This null hypothesis was rejected. Analysis of Variance indicated there were significant differences between writings in unrestricted spatial substrates and writing confined to small boxes and short lines. Descriptive statistics revealed that nearly all the subjects in the present study altered their handwriting to accommodate spatial restrictions. The second null hypothesis indicated that there would be no 
significant difference in written entries over pre-existing lines and writings. Because nearly all respondents altered their writings to some degree to avoid writing over lines, a statistical test was determined to be unnecessary. This null hypothesis was rejected. The third null hypothesis indicated that there would be no significant difference concerning signs of reflex of avoidance based on the demographic characteristics of the sample (age, gender, handedness, educational level). Based on contingency table analysis using Chi-Square, this hypothesis was not rejected. Reflex of avoidance appears to occur without regard to age, gender, handedness, or educational level. 


\section{CHAPTER 5}

\section{DISCUSSION}

The purpose of the current study was to investigate and explore the concept of reflex of avoidance in handwriting and its implications for forensic document examiners. The study found that most people will alter their handwriting to accommodate spatial restrictions. This supports the contentions and assumptions of authorities in the forensic document examination discipline. In addition, the present study has indicated that reflex of avoidance in handwriting occurs not only in attempts to deceive or inconspicuously insert handwritten entries but also in normal insertions where there is no intention to deceive. However, it is much more apparent in efforts to make the handwritten entry unnoticeable.

Reflex of avoidance is identified when compression (vertical and/or horizontal) occurs in a handwritten entry. Horizontal compression is most apparent in writing on short lines, while vertical compression is most apparent in writings within boxes or between lines. Reflex of avoidance is also common with insertions between handwriting already present. The writer typically tries not to write over existing lines. It is not known why most people depict this characteristic.

The present study has also indicated that while reflex of avoidance does tend to distort the normal handwriting of an individual, forensic document examiners can still identify the writing based on traditional handwriting identification methods. Letter formations and proportional spacings were not significantly altered to the point that identification could not be made. Certain letter formations, particularly the ascending and descending strokes, may be altered to avoid crossing over existing lines. Also, baseline adherence is typically altered to 
avoid writing over existing lines. This may affect the line quality of the handwritten entries to some degree and may be considered an extrinsic influence on the handwritten insertion (Huber \& Headrick, 1999).

While reflex of avoidance generally does not distort the handwriting to the point document examiners could not render identification, it may prove useful for the document examiner to have exemplars written in the same manner for comparison purposes. This is especially true for questioned signatures written within box restrictions or in limited spatial substrates such as check endorsements and digital tablets. The document examiner may benefit from knowing the exact measurements of the writing area on the tablet itself.

\section{$\underline{\text { Findings }}$}

The findings of the current study suggest that forms of reflex of avoidance occur with frequency under both authentic and nonauthentic conditions. The Thomas Jefferson signatures, provided by the participants, displayed noticeable signs of reflex of avoidance by the writer when given a limited amount of space. Although significant changes did not occur vertically, the horizontal compression of writing and letter spacing was visibly significant. When insertions or additions were made by the participants, nearly all of the individuals condensed their writing in order to stay within the designated boundaries. The alteration of numbers and letters also indicated signs of reflex of avoidance. These findings supported two of the original hypotheses involving significant differences in the size of handwriting written in a limited space as opposed to handwriting written in an unlimited space and handwriting variations in an attempt to avoid preexisting writings. Demographics such as age, handedness, and gender did not, however, significantly portray reflex of avoidance tendencies. 
Certain sampling and demographic limitations restricted the study. A larger sample size may have demonstrated a significant difference between certain demographics and reflex of avoidance propensities. Implications of these possible differences were seen in the number alteration section of the survey wherein the majority of females portrayed signs of reflex of avoidance. An additional limitation was considered after the findings were rendered: some participants were less deliberate in the making of additions - imitations that would be likely to occur in a realistic or authentic scenario. This type of response may occur because the survey provides the participant with little to no incentive to complete the tasks accurately and effectively. The individual who feels as though he or she may have something to gain will be more likely to execute careful and deliberate additions or alterations to documents. Therefore, the study of cases involving nonauthentic additions made under varying conditions may more accurately depict signs of reflex of avoidance.

\section{$\underline{\text { Further Research }}$}

The current research examined the innovative concept of reflex of avoidance; therefore, further research regarding this topic is paramount in advancing the field of forensic document examination. A few areas in need of further investigation concerning this topic are: the use of digital tablets, early childhood development in handwriting, and reflex of avoidance reflected under fraudulent conditions.

As detailed previously in this study, signatures on digital tablets are coming into common use as a result of the exponential advancement of technology. Individuals are required to use these electronic devices during every day course of business work. The digital tablet provides a very limited amount of space in which to provide requested information. Research concerning 
signatures executed under these conditions may help to further establish the key characteristics of reflex of avoidance in regards to signature variations and/or alterations.

Furthermore, the potential to contribute to the knowledge of reflex of avoidance involves the influence of writing instruction during early childhood development. Specific instructions often commence when a child first begins to color. Parents and teachers instruct the child to color within certain parameters or inside the lines. As the child develops and begins the processes of printing and writing, he or she is taught to write within certain areas while avoiding other areas not designated for the written word. This process of instruction reinforces reflex of avoidance propensities that begin early in the child's writing development. The study of these foundational concepts along with possible gender differences concerning the conformity of coloring and/or writing within the lines may help to further explain why reflex of avoidance occurs and why it may be more predominant in specific individual's writings.

Lastly, and possibly most pertinent to research concerning this topic, is the need for investigation concerning signs of reflex of avoidance concerning fraudulent additions and alteration of documents. Nonauthentic additions and alterations occur in relation to such documents as wills, checks, bank statements, medical records, etc. The knowledge gained through research into specific reflex of avoidance characteristics under thusly prepared conditions will further assist document examiners in the detection of fraudulent additions and/or alterations. 


\section{REFERENCES}

Bird, C., Found, B., \& Rogers, D. (2010). Forensic document examiners'skill in distinguishing between natural and disguised handwriting behaviors. Journal of Forensic Sciences, 55, $1291-1295$.

DeAngelis, C. M., (1997). Effects of writing surfaces and author's position on handwriting. Journal of Questioned Document Examination, 6, 10 - 70.

Dyer, A. G., Found, B., \& Rogers, D. (2008). An insight into forensic document examiner expertise for discriminating between forged and disguised signatures. Journal of Forensic Sciences, 53, $1154-1159$.

Dyer, A. G., Found, B., \& Rogers, D. (2006). Visual attention and expertise for forensic signature analysis. Journal of Forensic Sciences, 51, 1397 - 1404.

Ellen, D. (2006). Scientific examination of documents: Methods and techniques, (3rd ed.) Boca Raton, FL: CRC Press.

Harralson, H. H. (2010). The NAS report: Implications for forensic document examiners. Journal of Forensic Document Examination, 20, 63 - 70.

Harralson, H. H., Teulings, H., \& Miller, L. S. (2011). Temporal and spatial differences between online and offline signatures. Paper presented at the meeting of the International Graphonomics Society, Cancun, Mexico.

Hecker, M. R. (1983). Effects of unusual paper supports on handwriting. Paper presented at the meeting of the American Society of Questioned Document Examiners, North Lake Tahoe, NV. 
Herkt, A., Boot, D., \& Walsh, D. (1999). Module 7: Structural and line quality inconsistencies. in B. Found \& D. Rogers (Eds.), documentation of forensic handwriting comparison and identification method: A modular approach. Journal of Forensic Document Examination, $12,37-44$.

Hilton, O. (1982). Scientific examination of questioned documents. New York, NY: Elsevier Science.

Huber, R. A. \& Headrick, A. M. (1999). Handwriting identification: Facts and fundamentals. Boca Raton, FL: CRC Press.

Kelly, J. H. (1978). An unusual writing surface - and considerations. Journal of Police Science and Administration, 6, $283-285$.

Kelly, J. S. \& Lindbolm, B. S. (2006). Scientific examination of questioned documents, (2nd ed.) Boca Raton, FL: CRC Press.

Koppenhaver, K. M. (2007) Forensic document examination: Principles and practice. Totowa, NJ: Humana Press.

Leung, S. C., Cheng, Y. S., Fung, H. T., \& Poon, N. L. (1993). Forgery I - Simulation. Journal of Forensic Sciences, 38, $401-412$.

Miller, L. S. (1987). Forensic examination of arthritic impaired writings. Journal of Police Science and Administration, 15, 51 - 55.

Miller, L. S., \& Harralson, H. H., (2006). Examination of tremor and distortion caused by extrinsic handwriting conditions. Journal of Forensic Document Examination, 64 - 82. 
Morris, R. N. (2000). Forensic handwriting identification. San Diego, CA. Academic Press.

Morton, S. E., (1980). How does crowding affect signatures. Journal of Forensic Sciences, 25, $141-145$.

National Research Council of the National Academies. (2009). Strengthening forensic science in the United States: A path forward. Washington DC, National Academy Press.

Nickell, J. \& Fischer, J. F. (1999). Crime scene: Methods of forensic detection. Lexington, KY: The University Press of Kentucky.

Osborn, A. S. (1929). Questioned documents. (2nd ed.) Mont Clair, NJ: Paterson Smith

Shraberg, D. (2011). Neurological disorders and their impact on handwriting analysis. Paper presented at the meeting of the Association of Forensic Document Examiners. Louisville, Kentucky.

Walton, J. (1997). Handwriting changes due to aging and Parkinson's syndrome. Forensic Science International, 88, $197-214$.

Zaki, N. N. \& Ibraheim, M. A. (1983). Effects of alcohol and canasbis sativa consumption on handwriting. Neurobehavioral Toxicology and Teratology, 5, $225-227$. 


\title{
APPENDIX
}

$\underline{\text { Data Collection Instrument }}$

\author{
Principal Investigator: L. Chris Rush Burkey
}

Title of Project: Reflex of Avoidance in Spatial Restrictions for Signatures and Handwritten Entries

\section{INFORMED CONSENT DOCUMENT}

\section{Purpose:}

The purpose of this research study is to determine if there are significant changes in handwriting based on the available writing space. The activity is for research purposes.

Procedure:

Subjects will be required to handwrite entries onto a form containing boxes and lines of various sizes. It is estimated that it will take about 20 minutes to complete the questionnaire.

Voluntary Participation:

Participation in this research experiment is completely voluntary. You must be age 18 or older to participate.

Contact for Questions:

If you have any questions, you may call Chris Burkey or Larry Miller at 423-439-5964. Confidentiality:

Every attempt will be made to see that your study results are kept confidential.

By signing below, you confirm that you have read or had this document read to you and that you are age 18 or older. You will be given a signed copy of this informed consent document. You have been given the chance to ask questions and to discuss your participation with the investigator. You freely and voluntarily choose to be in this research project. 
Directions: Use your normal cursive handwriting style to complete the following. Unless specifically instructed, use ink, not pencil.

1. In the space below, sign the name Thomas Jefferson three times.

1.

2.

3.

2. In the box below, sign the name Thomas Jefferson.

3. In the box below, sign the name Thomas Jefferson.

4. On the lines below, sign the name Thomas Jefferson three times. 
1.

2.

3.

5. On the lines below, sign the name Thomas Jefferson three times.

1.

2.

3.

6. On the lines below, sign the name Thomas Jefferson three times.

1.

2.

3.

7. Write the following appointment book entries on the lines provided below:

December 14 - 10:00 a.m. Appointment with John Doe.

December 16 - 9:30 a.m. Closing at bank on Doe property. 
8. Write the following patient exam notes in the box below:

January 15, 2011. Examined patient and discussed surgery procedures.

January 17, 2011. Spoke with patient on phone and advised that surgery was scheduled for January 24, 2011 at 7:30 a.m., Northside Hospital.

9. Add two zeros to the numeral 10 below, turning the 10 into 1,000

10. Change the amount $\$ 10.00$ below to read $\$ 1,000.00$

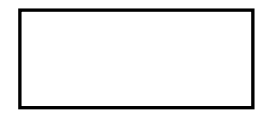

11. Assume you are cheating on a test that has already been graded. Change the A to a B in the answer below. You may use an eraser and pencil (provided) to do this. 
1.

12. Add a 9 and a 5 to the numeral 10 below to make it 9,510

13. Add a 6 and a 4 to the numeral 10 below to make it 6,410

14. Return to number 7 above and directly insert the following appointment book entry in between the December $14^{\text {th }}$ and December $16^{\text {th }}$ entries:

December 15 - 11:00 a.m. Final walkthrough of property with John Doe.

15. Return to number 8 above and insert the following for January 15 and make it appear as though it had NOT been written after the January $17^{\text {th }}$ entry:

Advised patient of dangers of using Zoloft prior to surgery. Patient stated they would not take medications prior to surgery. 
16. Insert the following in the will below and try to emulate the handwriting style so that those reading it will think it is part of the will:

I also give my nephew, John, all my stocks and the house.

\section{Demographics}

Your Age in years:

Your Gender: Male: Female:

Your Handedness: Right Handed: Left Handed:

(if you completed this exercise with a different hand, please indicate)

Your Educational level:

High School Only:

Some College:

College Graduate:

Post Graduate: 


\section{VITA}

\section{LINDE CHRISTINE RUSH BURKEY}

Personal Data:

Education:

Specialized Experience:

Awards:
Date of Birth: June, $3^{\text {rd }} 1980$

Place of Birth: Knoxville, TN

Marital Status: Married

B. S. Criminal Justice \& Criminology and

Psychology, East Tennessee State

University, Johnson City, TN 2009

Summa Cum Laude

Graduate Certificate in Forensic Document

Analysis, East Tennessee State University, Johnson City, TN 2010

M. A. Criminal Justice \& Criminology, East Tennessee State University, Johnson City, TN 2012

Apprenticeship - Forensic Document Examination April 2009 - April 2011

Graduate Assistant, Teaching Assistant August 2010 - May 2012

Forensic Document Examiner and Assistant April 2011 - Present

Alpha Phi Sigma Treasurer 2011-2012

Faculty Award - CJCR 2010

Outstanding Student of the Year Award - CJCR 2010 